\title{
ANALISA LINEAR SUPERPOSITION DALAM KELOLA GETARAN TANAH HASIL PELEDAKAN PADA PERTAMBANGAN BATUBARA
}

\author{
Dhion Pradatama. DM ${ }^{1)}$, Chani Pradasara ${ }^{2)}$, Syarif Nurdiansyah ${ }^{3)}$ \\ ${ }^{1,2)}$ Technical Services Engineer, ${ }^{3)}$ Area Manager PT Multi Nitrotama Kimia \\ ${ }^{1)}$ dhion@mnk.co.id, ${ }^{2)}$ chanipradasara@mnk.co.id, ${ }^{3)}$ syarif@mnk.co.id
}

\begin{abstract}
ABSTRAK
Getaran tanah merupakan getaran yang ditimbulkan akibat dari proses peledakan tambang. Selama ini getaran tanah dianggap sebagai waste energy yang dapat merusak dan menjadi isu terhadap lingkungan di sekitar area tambang. PT. Multi Nitrotama Kimia sebagai perusahaan jasa peledakan dan penjualan bahan peledak di Indonesia memiliki kustomer dengan isu demikian, salah satunya adalah PT Adaro Indonesia. Guna menanggulangi isu tersebut, maka dilakukan rekayasa teknik terhadap getaran tanah yang dihasilkan dengan merubah waste energy menjadi work energy dengan prinsip linear superposition menggunakan metode signature hole analysis (SHA) dan dioptimalkan dengan aplikasi inter-deck delay pada lubang double-deck untuk meminimalisir getaran tanah yang ditimbulkan. Penelitian dan percobaan dilakukan menggunakan metode Signature Hole Analisys (SHA) untuk merekam perambatan gelombang di setiap range blok - strip tertentu terhadap area konsen. Gelombang yang telah terekam selanjutnya dianalisis dengan fitur Linear Superposition untuk mendapatkan rekomendasi waktu tunda beserta prediksi getaran yang ditimbulkan. Rekomendasi waktu tunda yang didapat adalah waktu tunda pada inter-hole, inter-row, dan inter-deck yang mana akan diterapkan untuk peledakan selanjutnya. Berdasarkan analisis menggunakan metode Signature Hole Analysis, rekomendasi waktu tunda yang diberikan dapat diterapkan untuk mengakomodir prinsip linear superposition gelombang. Penerapannya dapat dioptimalkan menggunakan inter-deck delay sehingga meminimalisir getaran tanah yang dihasilkan. Dibuktikan oleh getaran tanah yang dihasilkan menggunakan rekomendasi tersebut selalu di bawah standar yang ditetapkan (PVS $=<2.00 \mathrm{~mm} / \mathrm{s}$ ).
\end{abstract}

Kaca Kunci : Getaran Tanah, Signature Hole Analysis, Linear Superposition

\begin{abstract}
One of the blasting process effect is ground vibration. Ground vibration currently consider as waste energy which it can infere and be an issue to the environment. PT. Multi Nitrotama Kimia as blasting service company and explosives sales in Indonesia has customers dealing with that issues, one of them is PT Adaro Indonesia. To overcome the issue, engineering approach is done to the ground vibration by changing waste energy into work energy with the principle of linear superposition using the signature hole analysis (SHA) method and optimized with the application of inter-deck delay on the double-deck hole to minimize the ground vibration. Researches and experiments are carried out using the Signature Hole Analysis (SHA) method to record wave propagation in each range of certain blocks - strips to the concern area. The recorded waves are analyzed with the Linear Superposition feature to obtain delay time recommendation along with the predicted vibration. The recommended delay time obtained is the delay time on inter-hole, inter-row, and inter-deck which will be applied for next blasting. Based on the Signature Hole Analysis method, the recommended delay time given can be applied to accommodate the linear superposition wave principle. Its application can be optimized
\end{abstract}


using inter-deck delay to minimize ground vibration produced. Its proven by ground vibrations produced using the recommendations always below the specified standard $(P V S=<2.00 \mathrm{~mm} / \mathrm{s})$.

Keywords: Ground Vibration, Signature Hole Analysis, Linear Superposition

\section{A. PENDAHULUAN}

Peledakan pada massa batuan mempunyai beberapa tujuan, yaitu : membongkar atau melepaskan batuan (bahan galian) dari batuan induknya atau memecah dan memindahkan batuan. Kegiatan peledakan dapat memberikan dampak ground vibration (getaran tanah), air blast (suara ledakan), flyrock (batu terbang). Ground vibration (getaran tanah) merupakan getaran yang ditimbulkan akibat dari proses peledakan. Selama ini getaran tanah dianggap sebagai waste energy yang dapat merusak dan menjadi isu terhadap lingkungan di sekitar area tambang. PT. Multi Nitrotama Kimia sebagai perusahaan jasa peledakan dan penjualan bahan peledak di Indonesia memiliki customer dengan isu ground vibration, yaitu PT Adaro Indonesia.

Pit Tutupan North merupakan salah satu area operasional PT Adaro Indonesia yang memiliki isu dengan lingkunga. Pit Tutupan North berada dekat dengan area kritis yaitu berupa infrastruksur perusahaan migas (Sumur, Tanki, Kantor) dan lingkungan penduduk (Gambar 1) dengan jarak yang sekarang hamper 100 - $1500 \mathrm{~m}$ yang mana menjadi perhatian terhadap pengaruh dari getaran tanah akibat peledakan (Gambar 2).

Sesuai dengan regulasi dari Standar Nasional Indonesia (SNI 7571:2010) tentang dampak getaran tanah akibat peledakan terhadap bangunan dan infrastruktur yang ada di sekitar area penambangan, mengharuskan getaran tanah yang dihasilkan dari peledakan di Pit Tutupan North harus $<2 \mathrm{~mm} / \mathrm{s}$ (Tabel 1). Guna menanggulangi isu tersebut, maka dilakukan rekayasa terhadap getaran tanah yang dihasilkan. Getaran tanah yang semula adalah waste energy dapat dirubah menjadi work energy dengan prinsip linear superposition menggunakan metode signature hole analysis (SHA) dan dioptimalkan dengan aplikasi inter-deck delay pada lubang double-deck untuk meminimalisir getaran tanah yang ditimbulkan.

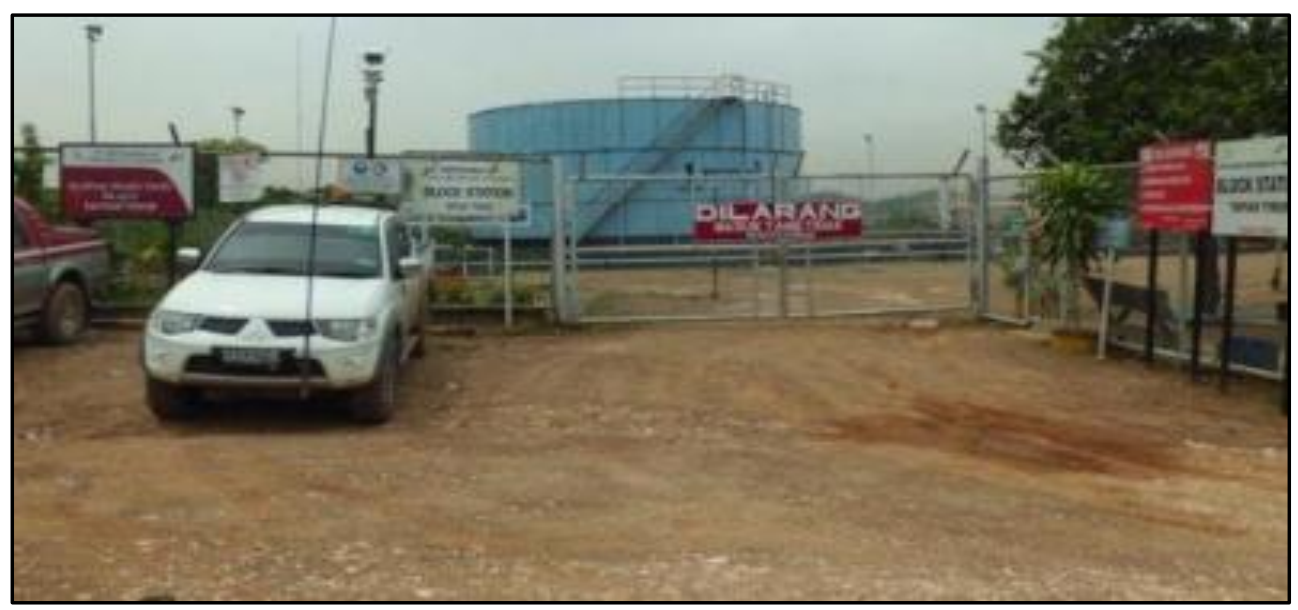

Gambar 1. Infrastruktur Perusahaan Migas Sebagai Titik Konsen Pit Tutupan North 


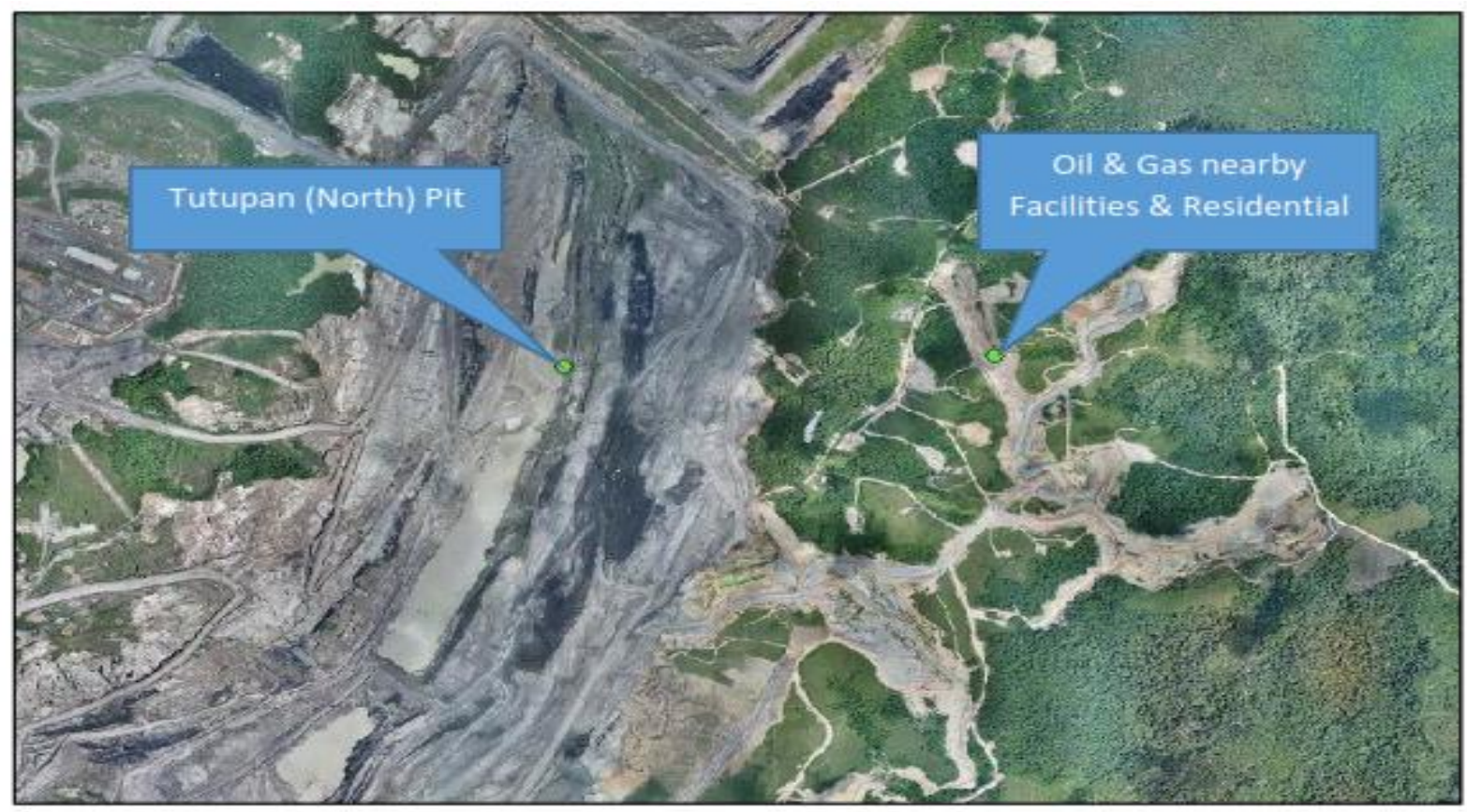

Gambar 2. Peta Pit Tutupan North dan Area Konsen

Tabel 1. Baku tingkat getaran peledakan terhadap kelas dan jenis (SNI 7571:2010)

\begin{tabular}{clc}
\hline Kelas & \multicolumn{1}{c}{ Jenis bangunan } & $\begin{array}{c}\text { Peak Vector Sum } \\
\text { (mm/detik) }\end{array}$ \\
\hline 1 & $\begin{array}{l}\text { Bangunan kuno yang dilindungi undang-undang benda } \\
\text { cagar budaya (Undang-undang No. 6 tahun 1992). }\end{array}$ & 2 \\
& $\begin{array}{l}\text { Bangunan dengan pondasi, pasangan bata dan adukan semen } \\
\text { saja, termasuk bangunan dengan pondasi dari kayu dan } \\
\text { lantainya diberi adukan semen. }\end{array}$ & 3 \\
3 & $\begin{array}{l}\text { Bangunan dengan pondasi, pasangan bata dan adukan semen } \\
\text { diikat dengan slope beton. }\end{array}$ & 5 \\
4 & $\begin{array}{l}\text { Bangunan dengan pondasi, pasangan bata dan adukan semen } \\
\text { slope beton, kolom dan rangka diikat dengan ring balk. }\end{array}$ & $7-20$ \\
& $\begin{array}{l}\text { Bangunan dengan pondasi, pasangan bata dan adukan semen, } \\
\text { slope beton, kolom dan diikat dengan rangka baja. }\end{array}$ & $12-40$ \\
\hline
\end{tabular}

Linear superposition merupakan suatu prinsip peluruhan gelombang dimana ketika dua fase gelombang (positif dan negatif) bertemu pada amplitudo yang hampir atau sama maka getarannya akan menjadi nol (Gambar 3). Prinsip inilah yang diujicobakan untuk mengatasi isu pada Pit Tutupan dengan merencanakan sedemikian mungkin waktu tunda (inter-row dan inter-hole delay) yang digunakan pada operasi peledakannya sehingga dapat mengakomodir prinsip linear superposition ini. Prinsip ini diharapkan dapat mengurangi getaran tanah hasil peledakan yang dihasilkan menjadi minim. Demi mendukung kinerja prinisip ini, maka perlu dilakukan terlebih dahulu Signature Hole Analysis (SHA) guna melakukan permodelan dan analisis gelombang pada area tersebut agar didapatkan waktu tunda (inter-row dan inter-hole delay) yang tepat. 


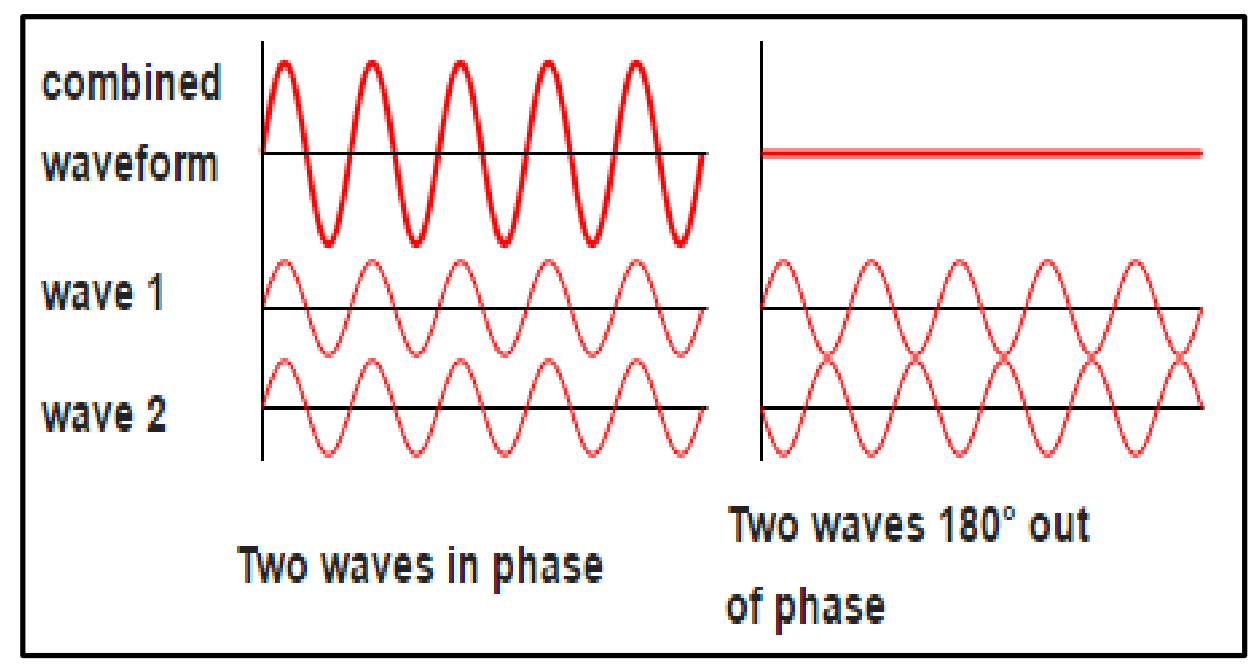

Gambar 3. Prinsip Linear Superposition gelombang

\section{B. METODOLOGI PENELITIAN}

Penelitian dilakukan dengan menggunakan metode Signature Hole Analisys (SHA) untuk merekam perambatan gelombang (background wave) di Pit Tutupan North terhadap area konsen. Signature Hole Analysis ialah metode dan analisis perekaman gelombang dari satu atau banyak lubang ledak standar. Tujuan dari Signature Hole Analysis ini adalah untuk memberikan informasi mengenai homogenitas masa batuan dengan rekaman rambat gelombang getaran yang dihasilkan dan ditangkap oleh alat ukur (blasting monitor).

Output dari signature hole analysis ada dua, yaitu analisis scaled distance, dimana akan didapatkan prediksi nilai getaran yang akan dihasilkan berdasarkan pada jumlah isian bahan peledak dengan jarak terhadap area konsen. Kedua adalah linear superposition dengan simulasi waktu delay yang dapat diterapkan pada kegiatan peledakan nanti. Pada metode signature hole, alat ukur (blasting monitor) ditempatkan secara paralel terhadap lubang ledak dan berada diantara dari lubang ledak dengan area konsen.

Oleh karena itu dilakukan peledakan signature hole di Pit Tutupan North. Signature hole analysis di Pit Tutupan North dilakukan dengan peledakan pada lima lubang standar dengan waktu tunda antar lubangnya yaitu $1 \mathrm{~m} / \mathrm{s}, 2.000 \mathrm{~m} / \mathrm{s}, 4.000 \mathrm{~m} / \mathrm{s}, 6.000 \mathrm{~m} / \mathrm{s}$, dan $8.000 \mathrm{~m} / \mathrm{s} \mathrm{s}$. waktu tunda didesain dengan waktu yang panjang bertuuan agar dalam pengolahan data dapat membedakan gelombang antar lubang yang terekam berdasarkan waktu tunda tersebut. Jarak lubang kelima dengan blasting monitor pertama dan kedua berturut-turut adalah $100 \mathrm{~m}$ dan $150 \mathrm{~m}$ (Gambar 4).

Setelah gelombang peledakan signature hole berhasil terekam, selanjutnya gelombang-gelombang tersebut akan dianalisis untuk mengeluarkan amplitudo gelombang tersebut keluar dari fasenya dengan prinsip linear superposition. Data gelombang tersebut dianalisis menggunakan software dengan advanced module, yang mana hasil analisisnya akan berupa simulasi waktu tunda (inter-row, interhole, dan inter-deck delay) dan prediksi nilai getaran yang dihasilkan (Gambar 5). 


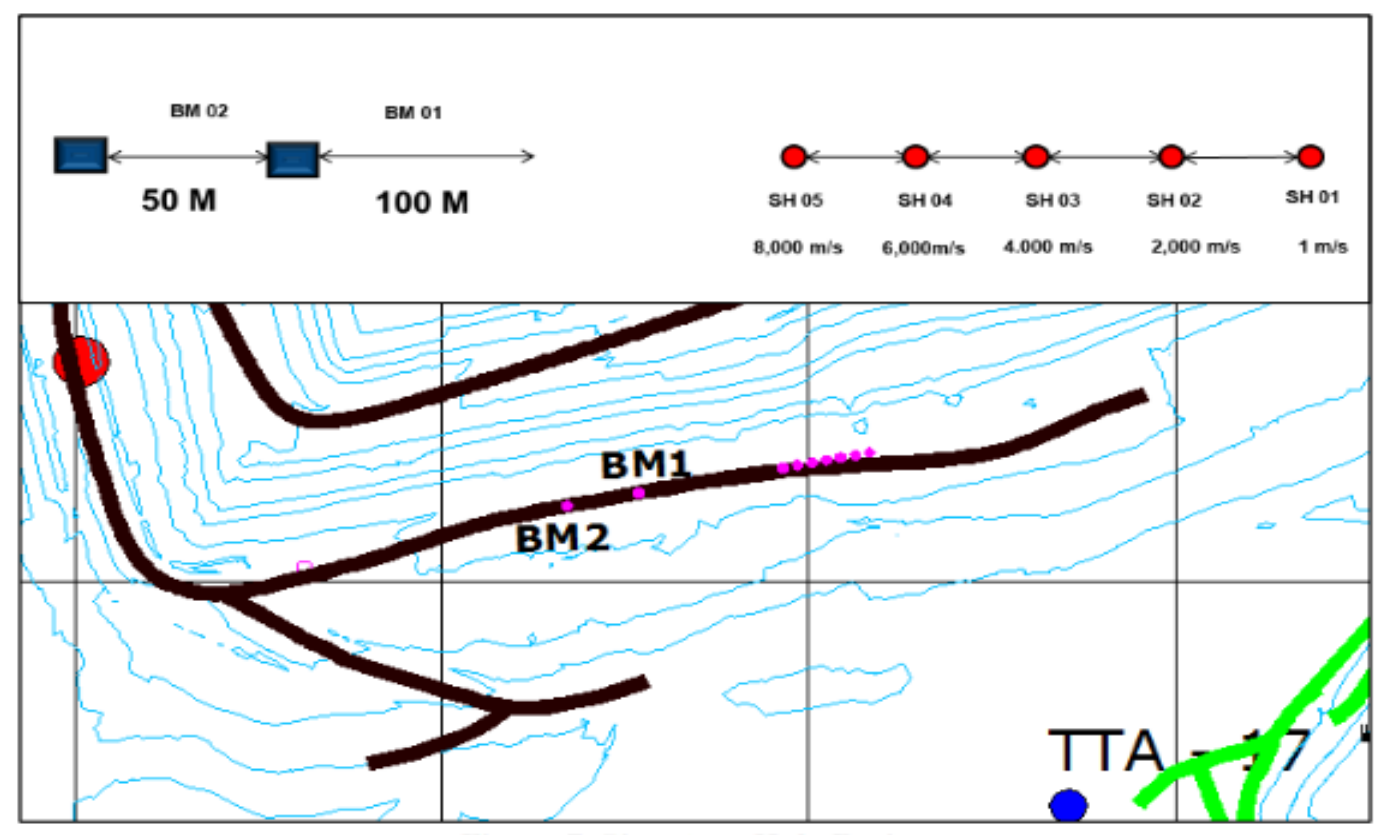

Gambar 4. Desain Peledakan Signature Hole

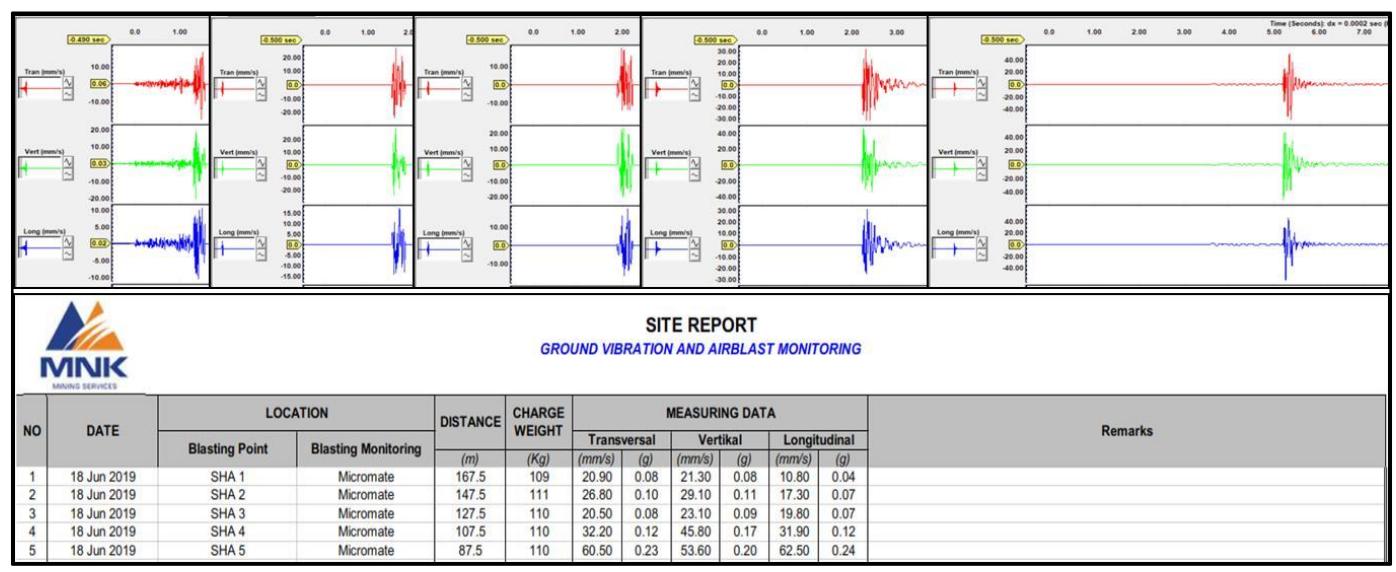

Gambar 5. Analisis Gelombang Signature Hole

\section{HASIL DAN PEMBAHASAN}

Dalam analisisnya dibutuhkan permodelan gelombang dan analisis mengularkan amplitudo gelombang dari fasenya dengan prinsip linear superposition untuk menghasilkan model gelombang yang komprehensif.

Setelah dilakukan analisis terhadap gelombang signature hole, maka akan didapatkan simulasi waktu tunda berupa inter-row, inter-hole, dan inter-deck delay, berdasarkan prinsip linear superposition, beserta dengan prediksi getaran yang akan dihasilkan (Gambar 6).

Berdasarkan analisis, waktu tunda (inter-row dan inter-hole) yang direkomendasikan untuk peledakan di area Pit Tutupan North adalah 54ms x 68ms untuk area North 1, 108ms x 108ms untuk area North 2, $31 \mathrm{~ms} \times 53 \mathrm{~ms}$ untuk area CT1, dan $47 \mathrm{~ms} \times 78 \mathrm{~ms}$ untuk area CT2 (Tabel 2). Waktu tunda yang 
direkomendasikan ini akan digunakan sebagai desain waktu tunda pada peledakan di Pit Tutupan North (Gambar 7).

Berdasarkan analisis menggunakan metode Signature Hole Analysis, rekomendasi waktu tunda yang diberikan dapat diterapkan untuk mengakomodir prinsip linear superposition gelombang. Penerapannya dapat dioptimalkan menggunakan inter-deck delay sehingga meminimalisir getaran tanah yang dihasilkan dan distribusi energy yang lebih baik. Penggunaan rekomendasi waktu tunda (inter-hole dan inter-row) ini harus diperbarui dengan melakukan signature hole analysis per periode waktu tertentu apabila terjadi perubahan yang signifkan pada elevasi rencana peledakan sehingga dapat mewakili area tersebut.

\begin{tabular}{|c|c|c|c|c|c|c|c|c|c|c|c|c|c|c|c|c|c|}
\hline \multicolumn{18}{|c|}{$\begin{array}{l}\text { II Signature Hole Anslysis Table } \\
\text { File }\end{array}$} \\
\hline Fikname & \multicolumn{3}{|c|}{ Blast Tning } & \multicolumn{4}{|c|}{ Peak. Paticle Velocity } & PVS & \multicolumn{4}{|c|}{ Doninart FfT Fiequency } & \multicolumn{4}{|c|}{ 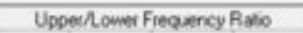 } & \multirow[t]{2}{*}{ - } \\
\hline 10oubin Cack & Deck & Holo & Row & & & & & Pevk & & & & & & & & & \\
\hline to vew] & Dedy & Deloy & Dely & Trant & Vent & Long & Peak & Vector & Trans & Vet & Long & Peat. & Tians & Ven & Long & Peak & \\
\hline & imsec & imsec & imsec: & {$[\mathrm{mm} / \mathrm{h}]$} & $(m=1 / x)$ & $(\mathrm{mm} / \mathrm{s})$ & $(m=\sqrt{a})$ & $\sin \Gamma$ & {$[\mathrm{Hz}]$} & {$[\mathrm{Hz}]$} & $\left|\mathrm{H}_{2}\right|$ & $|\mathrm{H} z|$ & & & & & \\
\hline A5OOH54R68 BWP & 0 & 54 & 68 & 19.70 & 21,60 & 19,70 & 21,40 & 2450 & 2.3 & 20 & 4.5 & 4.5 & 0,689 & 0.230 & 0.557 & 0.597 & \\
\hline A50OH68R54 BWP & 0 & 69 & 54 & 19,70 & 21.60 & 19,70 & 21,40 & 24.50 & 23 & 20 & 4.5 & 4.5 & 0.687 & 0.230 & 0,557 & 0.697 & \\
\hline A5OQH53ค67 BWP & 0 & 53 & 67 & 21,90 & 23,90 & 21,70 & 23,90 & 26,00 & 2,3 & 20 & 4.5 & 4.5 & 0.605 & 0.234 & 0.625 & 0,625 & \\
\hline A50OH67R53 BWP & 0 & 67 & 53 & 21.80 & 23,90 & 21,70 & 23,90 & 26,80 & 23 & 20 & 4.5 & 4.5 & 0.605 & 0.234 & 0.625 & 0.625 & \\
\hline A5DOH4BRE3 BWP & 0 & 48 & 63 & 21,00 & 26.20 & 22.60 & 24.20 & 27,00 & 2,3 & 20 & 23 & 2,3 & 5.140 & 1,830 & 3,920 & 5,140 & \\
\hline A500H163R48 BWP & 0 & 63 & 48 & 21.00 & 24,20 & 22,60 & 24.20 & 27,00 & 2,3 & 20 & 23 & 2.3 & 5,140 & 1.850 & 3,960 & 5.140 & \\
\hline R5DOH52RES BWP & 0. & 52 & 66 & 23,50 & 23,70 & 2280 & 23.70 & 27,20 & 2,3 & 20 & 4.5 & 4.5 & 0,706 & 0.277 & 0.657 & 0,706 & \\
\hline R5OOH6ER52 BWP & 0 & 66 & 52 & 23.50 & 23,70 & 22.80 & 23,70 & 27,20 & 23 & 20 & 4.5 & 4.5 & 0,706 & 0.27 & 0.657 & 0,706 & \\
\hline A5OOH4BRCO BWP & 0 & 48 & $\theta 0$ & 2500 & 23.90 & 20,50 & 25,00 & 2820 & 187.0 & 20 & 3,3 & 187.0 & 0.759 & 0334 & 1.030 & 1.030 & \\
\hline A5OOH50R65 BWP & 0 & 50 & 65 & 2700 & 2490 & 20.20 & 27.00 & 28.20 & 2.3 & 20 & 23 & 2.3 & 0.045 & 0.018 & 0,036 & 0.045 & \\
\hline A500H65A50 BWP & 0 & 65 & 50 & 2700 & 24.90 & 20.20 & 27.00 & 2820 & 2.3 & 20 & 2.3 & 2.3 & 0.045 & 0.018 & 0.036 & 0.045 & \\
\hline A500H68RS5 BWP & 0 & 68 & 95 & 2200 & 22.70 & 18,10 & 22.70 & 28.20 & 10.5 & 42.5 & 3.5 & 42.5 & 0.053 & 0015 & 0.042 & 0.053 & \\
\hline A5OOH60R48 BW/P & 0 & 80 & 48 & 2500 & 23.90 & 20.50 & 25,00 & 28.20 & 187.0 & 2.0 & 33 & 187.0 & 0.759 & 0334 & 1030 & 1.030 & \\
\hline A5DOH95R68 BWP & 0 & 95 & 68 & 2200 & 22,70 & 18,10 & 22.70 & 28.20 & 10.5 & 425 & 3.5 & 42.5 & 0.053 & 0.015 & 0.042 & 0.053 & \\
\hline
\end{tabular}

Gambar 6. Output analisis gelombang signature hole berdasarkan linear superposition

Tabel 2. Rekomendasi Inter-Hole dan Inter-Row Pit Tutupan North

\begin{tabular}{ccccc}
\hline Tutupan Sub Area & & Inter-Hole $(\mathrm{ms})$ & \multicolumn{2}{c}{ Inter-Row $(\mathrm{ms})$} \\
\hline North 1 & 54 & 68 & 68 & 54 \\
North 2 & 108 & 108 & 108 & 108 \\
CT 1 & 31 & 53 & 53 & 31 \\
CT 2 & 47 & 78 & 78 & 47 \\
\hline
\end{tabular}




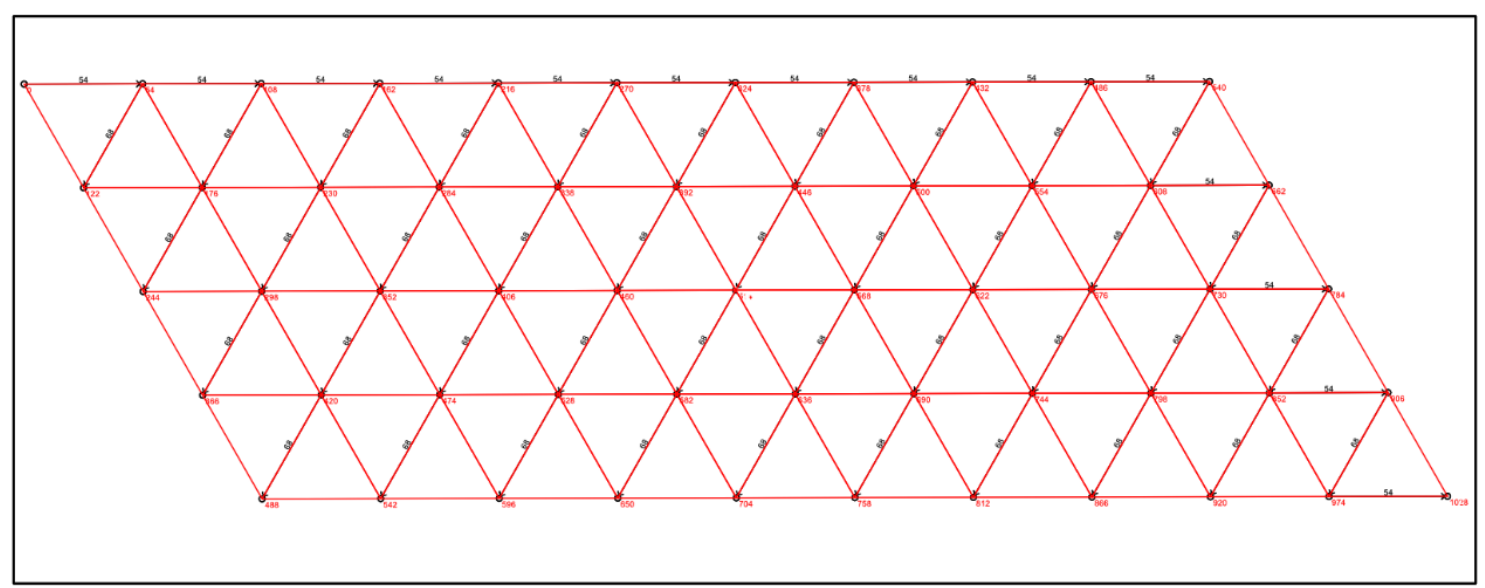

Gambar 7. Desain Peledakan berdasarkan prinsip linear superposition

\section{KESIMPULAN}

Berdasarkan analisis signature hole dan hasil rekomendasi melalui prinsip linear superposition yang kemudian diimplementasikan pada peledakan di Pit Tutupan North menunjukkan hasil yang positif. Dibuktikan oleh hasil getaran tanah rata-rata yang dihasilkan selama kegiatan peledakan pada tahun 2019 di Pit Tutupan North dengan menggunakan rekomendasi tersebut selalu tidak melebihi batas maksimal PPV yang ditetapkan (PVS $=<2.00 \mathrm{~mm} / \mathrm{s}$ ) (Gambar 8) dengan menggunakan desain interrow dan inter-hole yang dapat mengakomodir prinsip linear superposition. Selanjutnya, sebagai improvemet lanjutan dapat dilanjutkan uji coba dengan optimalisasi delay menggunakan inter-deck delay berdasarkan prinsip linear superposition.

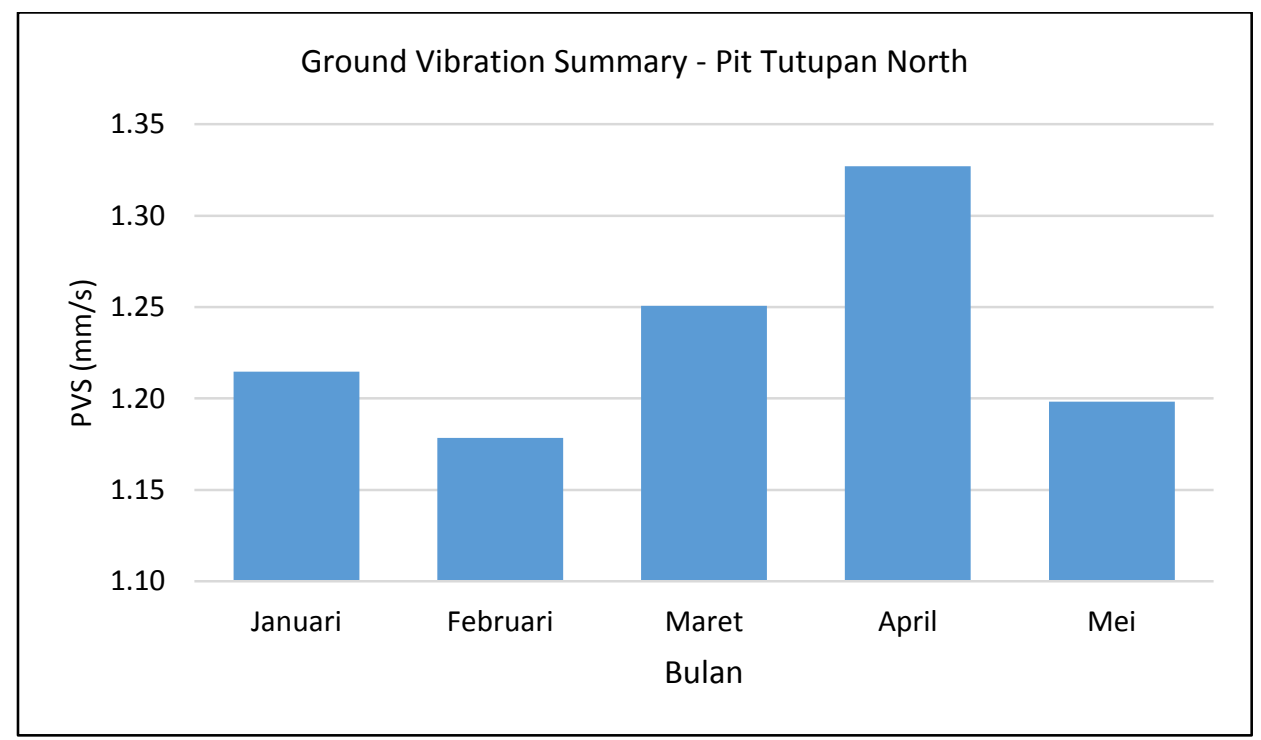

Gambar 8. Rangkuman Hasil Getaran Tanah di Pit Tutupan North 


\section{UCAPAN TERIMA KASIH}

Penulis ingin mengucapkan terima kasih kepada PT.Adaro Indonesia sebagai pelanggan PT.Multi Nitrotama Kimia yang memberikan dukungan dan persetujuan mereka untuk menerbitkan makalah ini

\section{DAFTAR PUSTAKA}

Hustrulid. W. (1999). Blasting Principles for Open Pit Mining. (Vol. 1, pp. 272-273). A.A. Balkema, Rotterdam, Brookfield. (2010). Blastware Operator Manual Handbook. (pp. 6.35-6.58). Instantel Inc., Ottawa, Ontario, Canada.

Yang, R., Scovira, D. S., \& Patterson, N. J. (2009). "An integrated approach of signature hole vibration monitoring and modeling for quarry vibration control". International symposium on Rock fragmentation by blasting, FRAGBLAST 9, pp. 597-605. 